\title{
Students' Level of Mathematical Comprehension and the Modified Moore's Method in Teaching Mathematics
}

\author{
Vima Socorro J. Tandog ${ }^{1}$, Maritess T. Jariolne ${ }^{2}$ \\ ${ }^{1}$ University of Science and Technology of Southern Philippines, Lapasan Highway, Cagayan de Oro City, Philippines \\ ${ }^{2}$ Cogon National High School, DepEd Division of El Salvador, El Salvador, Misamis Oriental, Philippines
}

\begin{abstract}
Teaching methods in Mathematics qualify and quantify the learning of the students. That explains why Mathematics educators today are concerned with the way the subject taught. This study was conducted to determine the effectiveness of a method in improving students' performance in Mathematics. This investigated the effect of modified Moore's method on students' achievement and conceptual understanding in the subject. Also investigated in this study is the relationship between mathematical comprehension and students' achievement and conceptual understanding in the subject. The grade 9 students in Cogon National High School, Cogon, El Salvador City constituted the sample of the study. A pretest-posttest quasi-experimental control group design was utilized. From among the three classes, two intact sections were chosen, one for the experimental group and the other for the control group. The experimental group was taught using the contemporary method. At start, a pretest on achievement, conceptual understanding and mathematical comprehension tests were given to the two classes. The same tests were administered after the experimental period. Mean, standard deviation, analysis of covariance and Pearson Product Moment Correlation were utilized to analyze the data. Results of the study revealed that at start, the two groups have comparable low scores in the pretest of the achievement test and in the three facets of understanding, namely; explain, interpret, and apply, and their scores were homogenous with very low standard deviation. In the posttest however, significant difference in the performance of the students in the achievement and conceptual understanding tests was observed in favor of those exposed to modified Moore's method. It was also found out that there is a significant relationship between students' mathematical comprehension skill and their achievement and conceptual understanding in Mathematics. The researcher recommends the use of modified Moore's method in teaching topics in grade 9 Mathematics and for the teachers to help students read, understand, and use Mathematical term, symbols, and expression.
\end{abstract}

Keywords: modified Moore's method, mathematical comprehension, achievement, conceptual understanding

\section{Introduction}

The international and the national assessments have always shown poor students' performance in mathematics. In the school year 2011-2012, the Department of Education (DepEd) of the Philippines conducted a National Achievement Test (NAT) for secondary high school students and the results showed that only $1.02 \%$ of fourth year students mastered Mathematics while $76.77 \%$ have average and low mastery. On the average, the fourth year students only obtained a mean percentage score of 48.90 (National Examination Testing and Research Center, 2013). The results have not improved the international assessment result of the Philippines which is ranked fourth and third from the bottom in the 2003 Trends in International Mathematics and Science Study and 2008 Advanced Mathematics Category, respectively (DepED, 2010)

Mathematical understanding is considered an important factor for students' performance in Mathematics. With the implementation of the spiral curriculum in the Philippines, it is necessary that students have good mathematical understanding of concepts in the lower year level to perform well in the next level. According to Piaget's theory of learning (1973), the learner moves from one stage of cognitive development to another through the process of equilibration, through understanding the underlying concept so that the understanding can be applied to new situation. However, many students reached secondary education with poor understanding of the basic concepts of Mathematics.

To alleviate the poor performance of students in Mathematics, teaching for conceptual understanding is demanded by leading Mathematics educators around the world. The NCTM (2000) standards urged teachers to teach students Mathematics with understanding. Ghazali and Zakari (2011) called for a reformation in teaching to promote conceptual understanding among students and minimize memorization. Cotton (2008) believed that a shift must occur in Mathematics instruction from role memorizing and performing algorithms, to critical thinking and conceptual understanding. He believed that students need conceptual understanding of Mathematics so they can effectively transfer the learned concept to solve unique problems in new situations. He further believed that when students have conceptual understanding, they can avoid many errors in solving problems.

How do we teach for conceptual understanding? Contrasting statements were observed from great philosopher, Vygotsky (1978) and from the towering figure in twentieth century Mathematics, Moore. For Vygotsky, learners need the intervention of the outside world in their acquisition of knowledge. Peers under their zone of proximal development can contribute much in the faster grasp of the desired learning. Hence, dialogue and group learning are important in educating students. While for Moore as stated by Parker (2005), acquisition of knowledge is an individual endeavour. 


\section{International Journal of Science and Research (IJSR) \\ ISSN (Online): 2319-7064}

Index Copernicus Value (2015): 78.96 | Impact Factor (2015): 6.391

He believed that students who were taught the least learned the more thus did not give lecture and prohibited students from collaborating and conferring with other students. For Moore, students learn best if they solve problems using their own skills of critical analysis and creativity.

Combining cooperative learning as advocated by Vygotsky and independent investigation as forwarded by Moore, the researcher found interest to investigate their effects on students' conceptual understanding and achievement scores in Grade 9 Mathematics. Furthermore, this study determined the influence of mathematical comprehension on students' performance. Mathematical comprehension is the ability of the learners to understand mathematical figures, symbols and words. Mullins, Martin and Foy (2013) revealed the impact of reading ability on TIMSS mathematics program. A significant difference is observed in the performance of the least proficient readers in items with high reading demands. Even in solving mathematical word problems, mathematical comprehension is a causative factor in students' ability to solve. If one cannot understand the mathematical terms, solving the problem will not be easy.

\section{Literature Review of Related Studies}

\section{Modified Moore's Method}

Findings from a number of studies showed that when students discover mathematical ideas and invent procedures, they have stronger conceptual understanding of connection between mathematical ideas. Sagun (2003) as cited by Sanches (2004) disclosed that giving students opportunity to discover and invent new knowledge and opportunity to practice what they have learned, improves their achievement. Aiyunden (2009) believed that lesson should be presented in practical inductive way and discovery in nature because the information the child discovered by himself will be easily learned and recalled than the information acquired by telling. This is supported by the findings of the study of Samuelsson (2008) which showed that exposing students to problem solving activities and discovering solutions lead students to progress significantly better in conceptual understanding, strategic competence and adaptive reasoning.

Moore's method of teaching is based on the principle of discovery learning. This is a method of Robert Lee Moore who is a towering figure in the twentieth century Mathematics and who is internationally recognized as founder of his own school of topology which produced some of the most significant mathematicians in the field. The unique features of this method is it virtually prohibit students from using textbooks during the learning process. Call for only the briefest of lectures in class demand no collaboration or conferring between classmates. Moore summed it up in just eleven words: "That student is taught the best who is told the least" (Parker, 2005)

Modified Moore's method is an alteration of the Moore's method to make it accessible to lower level classes and to facilitate the use of traditional materials and texts while still emphasizing students' presentation (Mahavier, 2004). It is based on the principle that students understand better and remember longer what they discover themselves than what is told to them and that people master the idea most thoroughly when they teach it to someone else. Mahavier further added that this method of teaching fits well with the current movement directed towards involving students more actively in the learning process. It prepares students for academic as well as industry by encouraging communication, presentation, critical thinking and writing skills while alleviating many of the difficulties that are experienced by teachers such as complacent students and students with poor work ethics. This method applies the same principle with that of guided discovery method.

Akanmu and Fajemidagba (2013) conducted a study on the effect of guided discovery learning on the performance of senior high school students in Mathematics and the influence of gender on the performance level of the students. Results revealed a significant difference in favor of those exposed to guided-discovery learning strategy compared to those not taught using this strategy. Through both male and female students performed equally well when taught using guided discovery strategy, the study showed that high scoring students benefited most while the performance of low scoring student was also enhanced. Thus, these researchers recommended among others that Mathematics teachers should make the teaching-learning of Mathematics interactive and activity-based so that students can gain knowledge and mathematical skills irrespective of the ability levels. This study is cited because modified Moore's method which was used in the present study is based on the principle of guided discovery.

Abdisa and Getinet (2012) investigated and contrasted the relative effectiveness of guided discovery method, demonstration and traditional lecture method of teaching on students' achievement in rotational motion. Their findings showed that the guided discovery method was the most effective teaching method. The findings also indicated that approximately $57 \%$ of the total variance in achievement of the students can be attributed to the specific teaching methods employed. There was no significant difference between the achievement of male and female students who were taught with guided discovery method, demonstration and the traditional method. There was a significant difference between the achievements of each pair of high-, medium- and low-achiever students' scores who were taught with the guided discovery method and demonstration. The students' achievement has a strong relationship with their background performance levels (high-, medium-, and low-achiever) besides the effect of the instructional methods. They recommend that teachers should implement guided discovery method with sufficient guidance to help students create, integrate and generalize knowledge.

In the study of Dhaher (2007) on the effect of modified Moore's method on learning and appreciation of proofs among college students, he found out that the method has a positive effect on students' conceptualization on mathematical proofs. Modified Moore's method also has positive effect on students' self-confidence on their abilities, on their appreciation of the relevance of proofs and on their ability to think independently. The modified Moore's method 


\section{International Journal of Science and Research (IJSR) \\ ISSN (Online): 2319-7064}

Index Copernicus Value (2015): 78.96 | Impact Factor (2015): 6.391

allowed students to experience Mathematics firs hand. Students built a coherent body of knowledge in which they created their own logical proofs. These results were supported by the findings of Cho, et al (2012) on their study on the effect of modified Moore's method on elementary number theory for gifted high school students. Students began to have confidence in writing mathematical proofs. They have the sense of ownership of their proof which boosted their self-esteem. In addition, the students enjoyed the course because the method used by the teacher brought curiosity and challenge.

\section{Mathematical Comprehension}

Mathematics appear to be the school subject in which students experience the greatest learning problem. For many secondary subjects, the cognitive skill required does not go beyond memory and language. In Mathematics memory and language are necessary but not sufficient for success. But if a student cannot comprehend the symbols and terms used, he cannot perform well in mathematics.

Adams (2003) described the skills that are missing for students to be able read Mathematics. To him, little attention is given on the basic notion of reading Mathematics as a language. Reading Mathematics is a multifaceted task because the reader is challenged to acquire comprehension and mathematical understanding with fluency and proficiency through the reading of numerals and symbols, in addition to words. Students across all grade levels who have weakness in their Mathematical ability if often due to the obstacles they faced in focusing on these symbols as they attempt to read the 'language' of Mathematics. He said that the greatest tool for helping students to succeed at reading the mathematical text is to teach students how to read the text, understand the meaning and then constantly practice these skills.

Draper (2012) in his document on comprehension strategies applied to Mathematics said that reading comprehension and writing strategies are parallel to strategies students need to be mathematically proficient. They must be keen in comprehending the terms in Mathematics because words and phrases that mean one thing in the world of Mathematics mean another in other context. For example, the word "similar" means "alike" in every usage, whereas in Mathematics similar has to have proportionality. The specialized symbols and technical language in Mathematics make the subject confusing. Students need to be aware of these confusing mathematical terms and symbols and the strategies to deal with them to perform well in the subject.

Many researchers consider that the ability to read Mathematics is important and a necessary skill for students to master, and that its benefits can be far reaching. Students who can read and comprehend mathematical text and language are better able to understand and succeed in Mathematics. Kenney, et al (2005) revealed that the biggest mathematical difficulty lies in the mathematical language itself. According to them, students know how to do the Mathematics processes but they do not understand what the question is asking. They lack the skill on how to read and understand mathematical text.

Buchanan (2007) discovered that daily use and practice of the mathematical language in both written and verbal form improved students' understanding of the textbook instructions, increased their vocabulary, and also increased their understanding of their Mathematics lesson. He also found out that students remembered the mathematical material better with constant use of mathematical language and terms.

The above-mentioned studies are related to the present once since it also deals with mathematical comprehension.

\section{Student-Student Discourse}

Many proponents of educational reform view the process of coming to know Mathematics as a social endeavor taking place during the interactions within a classroom community, interactions which provide an opportunity for students to learn through thinking, talking, agreeing, and disagreeing about Mathematics. Students' participation in the discoursebased classroom is essential as they are called to inquire and challenge the ideas presented by peers, the teacher and textbooks. The strategy gives students the opportunity to meaningfully explore their own mathematical ideas, articulate them and to examine the thinking offered by others. Lampert (1989) as mentioned by Nathan and Knuth (2003) supported the formation of new knowledge in her Mathematics classroom to construct a new idea as a joint venture in the class rather than a communication from teachers to students. She believed that Mathematics education must use classroom discourse to develop in students the idea of doing Mathematics of conjecturing, scrutinizing, and defending one's ideas, and at the same time learning about it.

Mendez (2010) examined how discourse can affect student learning. According to her, by orchestrating and promoting discourse, teachers can actively engage students in mathematical thinking. If students explain and discuss the strategies and process they use in solving the mathematical problem, they can connect their own everyday language to the specialized vocabulary of Mathematics. Furthermore, through discourse, teachers can have better understanding of the mathematical needs of the class, on what the students know, their misconceptions and how these might have developed.

Substantial evidence demonstrates that discourse in the Mathematics classroom can be powerful in supporting students' learning. Hiebert and Wearne (1993) investigated the performance of second-grade pupils in arithmetic under an instruction where they are exposed to fewer problems and spent more time on each problem. They were asked more questions requiring them to describe and explain alternative strategies and talked more using longer response. Results showed that those under discourse classroom gained more and showed higher level of performance than those taught in traditional method. The same result is found by Oughton (2010) in her study on the effect of student-student discourse in adult numeracy classrooms. Her study took advantage of 


\section{International Journal of Science and Research (IJSR) \\ ISSN (Online): 2319-7064}

Index Copernicus Value (2015): 78.96 | Impact Factor (2015): 6.391

the increased use of discursive group work in such classrooms where students worked collaboratively on mathematical activities with little intervention form the teacher. The positive result illustrated the potential of the method to afford insights into students' experiences of learning. These studies are relevant because modified Moore's method also employs discourse.

Bradford (2007) used mathematical dialogue activities in her study as an intervention for low achieving high school students in pre-algebra based on the recommendations of the Professional Standards for Teaching Mathematics on the use of teaching methods that provide opportunities for student discourse. Two distinct classes were taught, one with dialogue activities and the other without. Result shows that classes using the dialogue activities were found to have more opportunities for student-led questions and explanations and displayed more indicators of students learning and positive attitudes than control group class. Students who participated in the mathematical dialogue activities had greater gains in mathematical achievement, grater gains in problem solving and have positive effects on student attitudes concerning selfconcept. Furthermore, her study discovered that mathematical dialogue activities are promising intervention strategy for low achieving students. Dialogue is also used in modified Moore's method.

Olmsted (2012) examined the effects of student discourse and high-press questioning on students' conceptual understanding in a fifth grade Mathematics student. He found out that these pedagogies promoted on-task student talk enabling students to develop and refine their understanding of the subject. The pedagogies also promoted cooperation within the classroom as students worked together to conceptualize some of the big ideas they investigated.

Small-group discourse appears to be a comfortable way for novice learners to approach a more expert discourse on proof. This is one of the findings of Remillard (2010) on her study on learning mathematical proof by undergraduate Mathematics majors. The students had a sense of community in the lesson on mathematical proof utilizing small-group discourse. She also discovered that the method could lead the students into discussion of topics with increasing sophistication. This method promotes mathematical experiences for learners that are more authentic in nature where the joy of mathematical discovery is not uncommon.

Rose (2005) found out that student-student discourse and journal writing showed a positive change on students' attitude towards Mathematics over the twelve-week period. She found out that the use of two strategies added to the students' sense of control and power in the Mathematics classroom. Students were able to explain verbally or in written language how a problem was solved and make the learning their own. She stated that discourse and journal writing are effective methods of teaching Mathematics.

Pagon (2013) studied on the effect of student-student discourse to the achievement of students. He found out that student discourse is an effective method of teaching in improving students' achievement in Mathematics. This method can enrich students' conceptual understanding because it allows students to discuss mathematical concepts in their own context which leads to better performance. His finding supported Polizon's (2013) study on the effect of mathematical discourse and journal writing to the performance of the students. She found out that studentstudent discourse has improved students' achievement and conceptual understanding. Their studies are related to the present study because in Moore's method students discover the concepts through discourse.

\section{Conceptual Understanding}

Conceptual understanding is one of the six learning principles put forward by the National Council of Teachers of Mathematics (NCTM) in its principles and Standards for School Mathematics (2000). This principle states that students must learn mathematics with understanding, actively building new knowledge from experience and prior knowledge. The National Research Council (2001) set forth in its document to help children learn Mathematics using different strands which included conceptual understanding. The standards are being intertwined with the NCTM in its Learning Principle which says that to be mathematically proficient, a students must have the following: 1) conceptual understanding which includes comprehension of mathematical concepts of operations and relations; 2) mathematical fluency which require students to possess skill in carrying out mathematical processes with speed, accuracy and flexibility; 3) strategic competence wherein students should possess ability to formulate, represent and solve mathematical problems; 4)adaptive reasoning which refers to the capacity to think logically about the relationship among concepts and situation; and 5) productive disposition that is to possess habitual inclination to see Mathematics as sensible, useful, and worthwhile, coupled with a belief in diligence and one's own efficacy.

Research by education professionals has generally supported reform in teaching Mathematics and has shown that children who focus on developing a deep conceptual understanding develop both fluency in calculations and conceptual understanding. Grouws and Cebulla (200) in their article, "Improving Student Achievement in Mathematics", believed that investigations have consistently shown that an emphasis on teaching for meaning has positive effects on student learning, including better initial learning, greater retention and an increase likelihood that the ideas will be used in new situations. Zakaria et al. (2010) as mentioned by Ghazali and Zakaria (2011) conducted a study on the level of conceptual understanding from topic sequences and series. They examined the relationship between conceptual understanding and achievement in Mathematics. The result revealed that conceptual understanding of students was at a low level and that there was a significant relationship between conceptual understanding and Mathematics achievement. This study was supported by Rahman (2006) who found out that students' concepts of algebra were very low. His study also determined that the relationship between students' mastery of mathematical concepts and attitudes was low, but anxiety did not correlate significantly with students' mastery concepts. These studies revealed that the cause of low mathematical 


\section{International Journal of Science and Research (IJSR) \\ ISSN (Online): 2319-7064}

Index Copernicus Value (2015): 78.96 | Impact Factor (2015): 6.391

achievement is the lack of conceptual understanding.

Local studies also revealed the significance of conceptual understanding on students' achievement. In the study of Seriña (2013), he found out that students exposed to the framework which focused on teaching for understanding performed better in Mathematics II compared to those students under dynamic learning framework. There is a significant difference on the conceptual understanding of students who explain, interpret, and apply the concepts which contributed to their better performance.

Burgos (2012) in her study determined the effects of the curriculum Understanding by Design on the achievement and conceptual understanding of student in Mathematics. She found out that students exposed to the UbD curriculum performed better than those under the conventional method of teaching. Furthermore, she found out that conceptual understanding of students is correlated with their performance in Algebra. She recommended the use of a model because it promotes conceptual understanding of students. The study using understanding by design is related to the present study because the UbD requires students to discover with the guidance of the teacher.

Garridos (2012) studied on the impact of understanding by design template on the students' understanding on the basic algebraic concepts of functions and relations based on the six facets of understanding. She found out that there is a significant difference on the students' explanation, interpretation, perspective, empathy and self-knowledge on the basic concepts in algebra and that students' level of understanding on the basic algebraic concepts of functions and relations are satisfactory enhanced and improved. She concluded that the template will lead to a more desirable impact on students' understanding. The templates engages students to discuss the concepts through the guide questions.

The above-mentioned studies have bearing on the present study because conceptual understanding is one of the variables measured here that could be affected by the methods used.

\section{Methodology}

\subsection{Design}

This study utilized the pretest-posttest non-comparable quasiexperimental control group design. To determine the effect of the modified Moore's method on the achievement and conceptual understanding of students, the control group was subjected to the contemporary method of teaching while the experimental group was taught using the modified Moore's method. Both groups were given pretest on achievement and conceptual understanding prior to the treatment and the same tests were given after the treatments as posttests. The mathematical comprehension scores of the students were also determined.

\subsection{Setting and Participants of the Study}

The participants of this experimental research were the Grade 9 students of Cogon National High School in school year 2014-2015. This school is under the jurisdiction of the youngest division of Department of Education Region X, the Division of El Salvador City, Misamis Oriental. The sections under study were heterogeneous sections. Most of the participants came from the interior barangays of El Salvador and majority of them are sons and daughters of farmers and factory workers.

\subsection{Statistical Treatment}

Mean and standard deviation were used to describe the achievement of the students, conceptual understanding and mathematical comprehension. And to determine the effect of the two methods of teaching on the achievement and conceptual understanding level of the students, the one-way analysis of covariance was used. Lastly, to determine the relationship on their achievement and conceptual understanding, Pearson Product moment correlation was used.

\section{Results and Discussions}

Table 3. Means, Standard Deviation and Mastery Levels of Sccres in the Achievement Test.

\begin{tabular}{ccccc}
\hline & \multicolumn{2}{c}{ Control Group } & \multicolumn{2}{c}{ Experimental Group } \\
& $X$ & $Y$ & $X$ & $Y$ \\
\hline Mean & 3.31 & 7.05 & 3.10 & 9.54 \\
SD & 1.98 & 3.17 & 1.72 & 3.96 \\
Mastery Level & $20.69 \%$ & $44.06 \%$ & $19.38 \%$ & $59.62 \%$ \\
\hline Legend: X-pretest & $Y$ - post test & & &
\end{tabular}

Table 3 shows the results of the pretest and posttest of the achievement test given to the grade 9 students in Mathematics. The control group has a mean higher than the experimental group but both groups are below $50 \%$ of the total points. This indicates that the students in the two groups have poor background in Geometry before start of the quarter as indicated in their low means and low mastery level. In the posttest, the experimental group has higher mean than the control group by 2.49 . The control group obtained an increase of 3.74 while the experimental group has 6.44 increase from the pretest. To determine whether there is a significant difference in the performance of the two groups as influenced by the methods of instruction, further analysis was done using Analysis of Covariance.

As to the variability of the achievement scores, Table 3 further shows that the standard deviation of the control group in the pretest is greater than the experimental group but the difference is not quite big. This means that the scores of the two groups in the pretest are close to each other. In the posttest, the standard deviation of the control group is less than the experimental group. The students in the two groups show varied ability in the achievement test after the experimental period but the experimental group becomes more dispersed than the control group. 


\section{International Journal of Science and Research (IJSR) \\ ISSN (Online): 2319-7064}

Index Copernicus Value (2015): 78.96 | Impact Factor (2015): 6.391

Table 4. Summary of the Analysis Covariance Results for Achievement Test

\begin{tabular}{cccccc}
\hline $\begin{array}{c}\text { Source of } \\
\text { Variation }\end{array}$ & df & $\begin{array}{c}\text { Adjusted } \\
\text { Sum of } \\
\text { Squares }\end{array}$ & $\begin{array}{c}\text { Adjusted } \\
\text { Mean } \\
\text { Square }\end{array}$ & $F$ & p-value \\
\hline $\begin{array}{c}\text { Treatment } \\
\text { between }\end{array}$ & 1 & 264.3 & 143.74 & 12.54 & 0.001 \\
Error within & 76 & 859.9 & 11.46 & & \\
Total & 77 & 1124.2 & & & \\
\hline$P<.05$ & & & & & \\
& & & & & \\
\end{tabular}

Table 4 shows the results of the analysis of covariance for the achievement test. The analysis yielded a probability value of 0.001 which is less than the critical value at 0.05 level of significance. This led the researcher to reject the null hypothesis. This means that there is a significant difference between the achievement's mean score of the experimental group of 9.54 and the control group mean score of 7.05. The control group of students was taught using the contemporary while the group was taught using modified Moore's method. This implies that the students taught using the modified Moore's method performed better in the achievement test than those taught the contemporary method. The 2.49 significant difference between two means in the post test as shown in table 3 may be attributed to the meaningful acquisition of knowledge that help students make stronger connection of concepts. In the method, students are actively involved in the learning process and they constructed their own understanding resulting to better assimilation of the concept leading to better achievement. This result supported the studies of Abdisa and Getinet (2012) which also revealed the statistical significant difference in the achievement in Mathematics of students in favour of modified Moore's method compared to other methods of teaching. Students understand better and remember more concepts that they discover themselves.

The next table, Table 5, shows the mean score, standard deviation, mastery level based on DepED standards, and qualitative description of the scores of the students in the three facts of understanding. It can be observed that in the three facets, the students both in control and experimental groups performed poorly in the pretest. The two groups performed below $10 \%$ mastery level in the facets of understanding. Both groups do not have a good background in Geometry. With the standard deviation below 2.0 in all facets in both groups, the scores of the students are close to each other implying their similar abilities.

\begin{tabular}{|c|c|c|c|c|}
\hline \multirow[t]{2}{*}{ Framework } & \multicolumn{2}{|c|}{ Control } & \multicolumn{2}{|c|}{ Experimental } \\
\hline & Pretest & Post Test & Pretest & Post Test \\
\hline \multicolumn{5}{|l|}{ Explain } \\
\hline Mean & 1.07 & 7.21 & 1.72 & 10.08 \\
\hline$S D$ & 1.37 & 4.33 & 1.40 & 4.48 \\
\hline Mastery Level & $5.35 \%$ & $36.05 \%$ & 8.60 & $50.40 \%$ \\
\hline Descriptive Level & Very Weak & Weak & Very Weak & Developing \\
\hline \multicolumn{5}{|l|}{ Interpret } \\
\hline Mean & 0.85 & 5.88 & 0.99 & 8.07 \\
\hline $\mathrm{SD}$ & 1.03 & 3.92 & 1.12 & 5.43 \\
\hline Mastery Level & $4.25 \%$ & $29.40 \%$ & $4.95 \%$ & $40.35 \%$ \\
\hline Descriptive Level & Very Weak & Weak & Very Weak & Developing \\
\hline \multicolumn{5}{|l|}{ Apply } \\
\hline Mean & 0.95 & 6.46 & 0.64 & 8.26 \\
\hline SD & 1.20 & 3.88 & 0.80 & 4.22 \\
\hline Mastery Level & $4.75 \%$ & $32.30 \%$ & $3.20 \%$ & $41.30 \%$ \\
\hline Descriptive Level & Very Weak & Weak & Very Weak & Developing \\
\hline
\end{tabular}

Mastery Level $=($ raw score + total soore $) \times 100 \%$
It can be observed in Table 5 that in the explain facet of understanding, students under the experimental group have higher mean score of 1.72 in the pretest compared to the control group mean score of 1.07 . With that, the mastery level of the experimental group, which is $8.60 \%$ based on the total score, is also higher compared to that of the other group with only $5.35 \%$. Based on DepED Order No. 73, s. 2012, both groups fall under very weak level. The two groups are homogenous with standard deviations that are almost equal, 1.40 for experimental and 1.37 for control. After the experimental period, there is an improvement of students' scores in the explain facet. The mean score of the experimental group became 10.08 while that of the control group became 7.21. The experimental group has higher scores in the posttest than the control group with 2.87 difference in the mean scores. The experimental group was able to master $50.40 \%$ of the concepts while the students under the control group were able to master $36.05 \%$ of the concepts. It can also be noted in the table that the description of the control group in the explain facet is still weak in the posttest while that of the experimental group belong to developing level which means that those taught using the modified Moore's method performed better in the explain facet. Furthermore, the standard deviations in the posttest of the experimental and control groups are 4.48 and 4.33, respectively, which are higher than the standard deviations in the pretest. This means that the two groups have scores which are widely dispersed after the experimental period. The brighter students performed well in the posttest but were pulled down by the slower learners who have difficulty in expressing their ideas.

Like in the explain facet of understanding, the two groups have very low mean score in the pretest of interpret facet of understanding. The experimental group got 0.99 mean score which is only 0.14 higher than the pretest mean score of the control group. Both groups showed a very little background in the concepts with their mastery level of $4.95 \%$ for the experimental group and $4.25 \%$ for the control group. They fall under the very weak level with almost homogenous scores in the pretest and have 1.12 and 1.03 standard deviations for the experimental and control groups, respectively. In the posttest, both groups showed better performance in the interpretation facet of understanding. The experimental group got 8.07 mean score and $40.35 \%$ mastery level while the control group has 5.88 mean score with $29.40 \%$ mastery level. This shows that the students taught using modified Moore's method got higher scores than those taught using the contemporary method. Table 5 also indicates that the scores of the experimental group are more widely spread than that of the control group, with 1.51 difference in standard deviation.

Table 5 also shows the performance of the students in the apply facet of understanding. The qualitative description indicates that the students in both groups performed very weak in the pretest. The experimental group got only 0.64 mean score with $3.20 \%$ mastery level while the control group got 0.95 mean score with $4.75 \%$ mastery level. With 0.80 standard deviation, the experimental group is a bit homogenous in their performance in the pretest compared to the 1.20 standard deviation of the control group. In the

\section{Volume 6 Issue 7, July 2017 www.ijsr.net}




\section{International Journal of Science and Research (IJSR) \\ ISSN (Online): 2319-7064}

Index Copernicus Value (2015): 78.96 | Impact Factor (2015): 6.391

posttest, the mean score of the experimental group is 8.26 which is higher than the mean score of the control group which is 6.46. This shows that the experimental group has higher scores in this facet compared to the control group with a mastery level of $41.30 \%$ and $32.30 \%$ for the control group. The qualitative description indicates that the students in both groups performed better, from category very weak in the pretest to category weak in the posttest for the control group and from very weak to developing for the experimental group. The standard deviation of 4.22 also indicates that those students taught using the modified Moore's method under the experimental group are a bit diverse in terms of their ability to apply the concepts learned compared to those under the contemporary method of teaching with 3.88 standard deviation. There are students who can do satisfactorily in the application of concepts but there are also some who cannot do correct application.

Comparing the performance of the students in the three facets of understanding, it can be observed in the Table 5 that in the pretest, students both in experimental and control groups have better scores in the explain facet. The mastery levels under the explain facet for the two groups were greater than $5 \%$ while for the other two facets, they were below $5 \%$. But using the levelling used by DepED, all of the scores of the students under experimental and control groups fall under the very weak level and all with standard deviations that are below 1.5. Prior to the lesson proper, students in both groups were very poor in explaining, interpreting, and applying concepts in Geometry as seen in their very low mastery level. With the very low standard deviation, they have scores that are close to each other. After the experimental period, variation of students' scores can be observed in both groups as shown in the increased standard deviation. The scores in the interpret facet under experimental group showed more disperse distribution of scores with standard deviation of 5.43 while the scores in the apply facet under control group are closest to each other with standard deviation 3.88. In the posttest, students under both groups showed higher scores in the explain facet and low performance in interpret facet. But in all facets, an improvement in the students' scores can be observed as their scores in the posttest fall under weak level from very weak in the pre-test for the control group and under developing level from very weak in the pre-test for the experimental group. In all facets, the experimental group performed better than the control group with more dispersed scores. This group was taught using the modified Moore's method.

To determine if there is significant difference on the conceptual understanding of the students between the contemporary and modified Moore's method, further analysis was performed.

Table 6. Summary of the Analysis of Covariance Results for Conceptual
Understanding Test

Table 6 shows the result of the analysis of covariance for the three facets of conceptual understanding. For the explain facet, the analysis yielded an $\mathrm{F}$ value of 66.82 , with probability value of 0.001 , which is less than the critical value of 0.05 level of significance. This gives evidence to reject null hypothesis that there is a significant difference in conceptual understanding of students under explain facet. This implies that students under the experimental class that are taught using the modified Moore's method have better performance in the explain facet of understanding. The significant difference may be attributed to the source of the knowledge gained. Those under the modified Moore's method of teaching worked hard to discover the concept. This may contribute to deeper understanding. Because the students themselves discover the concept through hard work by experiencing different methods just to solve and derive the concept, they can better explain the concept because their understanding is deeper and more meaningful. The finding of this study agrees with those of Akanmu and Fajemidagba (2013) where they found out that modified Moore's method was more effective than conventional method on students' acquisition of concepts in the teaching-learning process. This also supports Samuelsson's findings (2003) in related studies where he found out that exposing students to problem solving activities and discovering solutions enhanced their adaptive reasoning.

For the interpret facet of understanding, the analysis resulted to a probability value of 0.001 which is less than the critical value of 42.25 at 0.05 level of significance. With the significant difference of the p-value at 0.05 level of significant, this provides evidence to reject the null hypothesis. There is a significant difference in the conceptual understanding of students under interpret facet. This implies that students under the experimental group have better performance compared to the students under the control group in the interpret facet of understanding. Those taught with the modified Moore's method can better interpret mathematical statements than those taught using the contemporary method. Under the modified Moore's method, students are more exposed on interpreting data and working on them alone with their group. The experience they have and the concepts they learned from it have deeper impact on their understanding. It also developed their critical thinking. This is similar to Abdisa and Getinet's findings (2012), where they found out that modified Moore's method was more effective in improving the performance of students in 


\section{International Journal of Science and Research (IJSR) \\ ISSN (Online): 2319-7064}

Index Copernicus Value (2015): 78.96 Impact Factor (2015): 6.391

all learning abilities.

The same result can be observed in the apply facet of understanding as shown in Table 6 . The analysis yielded Fvalue of 42.69 with p-value of 0.001 . The null hypothesis is rejected because the critical value is greater at 0.05 level of significant. There is a significant difference in the conceptual understanding of students in apply facet. This implies that even in the apply facet of understanding, the experimental group performed better than the control group. Those under the modified Moore's method can apply better the concepts learned compared to the students taught using the contemporary method. With the method, the students arrived at an understanding of new concept on their own through making connection of previously learned concept to the problem presented and testing possible methods that could unlock the concept. This developed their strategic competence. The ownership students have with the knowledge gained make learning better and deeper. This could contribute to the better performance in application of concepts. This finding agrees with that of Samuelsson (2008) where he found out that students' progress in conceptual understanding and strategic competence significantly better when exposed to problem-based curriculum. The finding also supports that of Dhaher (2007) that showed the positive effects of modified Moore's method on students' conceptualization of mathematical proofs and their ability to think autonomously and create their own proofs. The method enhanced students ability to apply concepts learned in solving problems.

Table 7. Correlation Matrix of Student's Mathematical Comprehension and Achievement Pre-test and Post-test Sorres

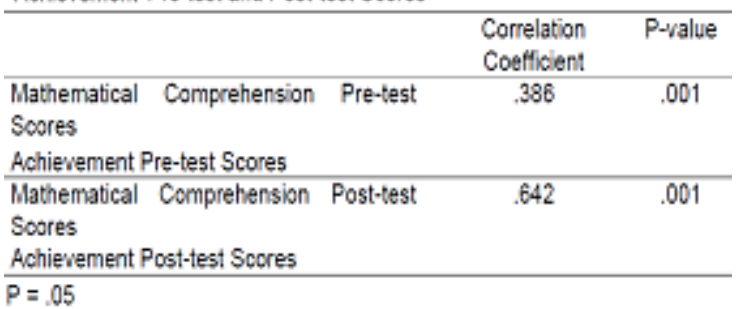

Table 7 presents the correlation between students' mathematical comprehension and achievement scores. The correlation coefficient between the pre-test scores of the mathematical comprehension and achievement test and between post-test scores of the two tests are 0.386 and 0.624 , respectively with p-value both equal to 0.001 . This led to the rejection of the null hypothesis. This implies that students' mathematical comprehension level has high relationship with their achievement score. Thus, if a student is very low in comprehending mathematical terms and expressions, his achievement in Mathematics will be highly affected. Because the student do not fully understand the languages in Mathematics, it is difficult for him to master the subject. As Buchanan (2007) stated, reading and understanding mathematical language improved students' performance in the subject.
Table 8. Correlation Matrix of Student's Mathematical Comprehension and Conceptual Understanding Pre-test and Post-test Scores.

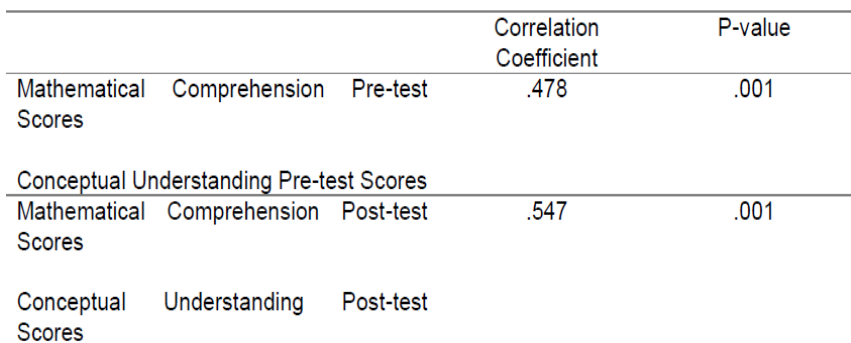

$p=.05$

Table 8 shows that the correlation coefficient between students' pre-test scores in mathematical comprehension and conceptual understanding tests and between the post-tes scores of the two tests are 0.478 and 0.547 , respectively. The p-values are both 0.001. The null hypothesis is rejected because this implies that students' mathematical comprehension is significantly correlated to their conceptual understanding. Students' ability to explain, interpret and apply concepts is greatly affected by their understanding of mathematical terms and expressions. A student cannot explain what he does not understand. His explain facet of understanding is affected with his knowledge of the symbols and terms in mathematics. The same is true for the interpretation and application facets of understanding. If given the data to interpret, understanding on the symbols and terms used is necessary. One cannot also apply his concepts learned if one does not understand what is being asked in the mathematics problem.

\section{Conclusions and Recommendations}

The modified Moore's method of teaching can contribute to the better achievement of students in mathematics. This method also helps improve the conceptual understanding of students in the subject. It also provides better opportunity for students to improve their achievement and conceptual understanding of geometry concepts and processes. And finally, students' performance in mathematics is affected by their mathematical comprehension.

Based on the findings and conclusions of the study, the researchers recommend that mathematics teachers may apply modified Moore's method in teaching topics in Geometry. Secondly, teachers may find ways to enhance the curriculum to foster better performance of the students in mathematics. They may teach the students to read, understand and use terms, symbols and expressions in mathematics and similar studies may be conducted using other topics in mathematics.

\section{References}

[1] A. Bonnaccorsi, Abdisa, G. and Getinet, T. (2012). The effect of Guided Discovery on Students' Physics Ahievement. Metu University, Ethiopia.

[2] Adams, T.L. (2003). Reading mathematics: More than words can say. The Reading Teacher, 56 (8), 786-795. 


\section{International Journal of Science and Research (IJSR) \\ ISSN (Online): 2319-7064}

Index Copernicus Value (2015): 78.96 | Impact Factor (2015): 6.391

[3] Akanmu, A.M and Fajemidagba, O.M (2013). "Guideddiscovery learning strategy and senior school students' performance in mathematics in Ejigbo, Nigeria." Journal of Education and Practice Vol. 4, No. 12, 2013.

[4] Aiyendun, J. (2009). Influence of Academic Ability of Students on Achievement in Secondary School Mathematics. University of Ilorin, Kwara State, Western Nigeria.

[5] Buchanan (2007). The Importance of Teaching Students How to Read to Comprehend Mathematical Language. University of Nebraska-Lincoln, Oshkosh, Nebraska.

[6] Burgos, E. (2012). Understanding by Design and Student Achievement in Mathematics. Unpublished Master's Thesis, Mindanao University of Science and Technology, Cagayan de Oro City.

[7] Bykerk-Kauffman, Ann (2013). Guided Discovery Problems. On the Cutting Edge - Professional Development for Geoscience Faculty.

[8] Carreira, A., Jones, N., \& Jacinto, H. (2014). Proceedings of the Problem @ Web International Conference: Technology, creativity and affect in mathematical problem solving. Faro, Portugal: Universidade do Algarve.

[9] Cho, K., Park, J., \& Kwon, O. (2012). Effects of modified Moore's method on elementary number theory for gifted high school student: an exploratory study. 12th International Congress on Mathematical Education. COEX, Seoul, Korea.

[10]Cotton, K.H (2008). "Mathematical Communication, Conceptual Understanding, and Students' Attitudes toward Mathematics". University of Nebraska-Lincoln, Oshkosh, Nebraska.

[11]Dhaher, Y. (2007). The effect of a Modified Moore's Method on Conceptualization of Proofs among College Students. Kent State University.

[12] DepED (2010). Department of Education. Research and Statistics Division. Fact Sheet as of 23 September 2010. Manila.' DepED Order No. 73, s. 2012

[13] Dewey, J. (1997). Democracy and Education. New York: Simon and Schuster. (Original work published 1916)

[14] Dickhauser, O. \& Meyer, W. (2006). Gender differences in young children's math ability attributions. Psychology Science. Volume 48

[15]Draper, D. (2012). Comprehension Strategies: Comprehension Strategies Applied to Mathematics. DECD Curriculum Consultant, Northern Adelaide.

[16] Garridos, C. (2012). Understanding by Design Template: Its Effects on Students' Six Facets of Understanding on the Basic Algebraic Concepts. Doctoral Dissertation, Mindanao University of Science and Technology, Cagayan de Oro City.

[17] Ghazali, N.H.C \& Zakaria, E. (2011). Students' procedural and conceptual understanding of mathematics. Australian Journal of Basic and Applied Sciences, 5 (7): 684-691

[18] Gillies, R. M. (2014). Cooperative Learning: developments in Research. International Journal of Educational Psychology. Vol. 3, No. 2. June 2014

[19]Good, C. (2006). Teaching by the Moore Method. University of Birmingham. MSOR Connections Vol. 6 No. 2
[20] Grouws, D. \& Cebulla, K. (2000). Improving student achievement in mathematics. International Academy of Education Educational Practices Series 4. 1000 Brussels, Belgium.

[21]Herrera, F. (2002). Group Activity Method: Its Influences on Students Performance in Elementary Statistics and Attitude towards Math (Master's Thesis). MPSC.

[22]Iqbal, Muhammad (2004). Effect of Cooperative Learning on Academic Achievement of Secondary School Students in Mathematics. Pakistan Research Repository.

Available: eprints.hec.gov.pk/388/1/239.html.htm

[23] Kenney, J.M., et al (2005). Reading in the mathematics classroom. In Literacy strategies for improving mathematics instruction (Chap. 2). Assn for Supervision \& Curriculum.

[24] Kolb, D. (1984). Experimental Learning: Experience as The Source Of Learning And Development. Available: http://www.businessballs.com/kolblearning styles.html

[25] Kozulin, et al (2003). Vygotsky's Educational Theory in Cultural Context. Cambridge University Press, United Kingdom.

[26] MacGregor, M. \& Price, E. (1999). An exploration of aspects of language and algebra learning. Journal for Research in Mathematics Education. 30 (4), 449-467

[27] Mullins, I., Martin, M. and Foy, P. (2013). The Impact of Reading Ability on TIMSS Mathematics and Science Achievement at the Fourth Grade: An analysis by Item Reading Demands. Prepared for IEA's 4th International Research Conference in Singapore 2013.

[28] National Council of Teachers of Mathematics (2000). Principles and Standards for School Mathematics. Reston, VA: NCTM.

[29] National Education Testing and Research Center, Department of Education. Available: www.deped.gov.ph

[30] National Research Council (2001). Adding It Up: Helping Children Learn Mathematics. Washington, DC: National Academy Press

[31]Nizoloman, O. (2013). Relationship between Mathematics Ability and Achievement in Mathematics among Female Secondary School Students in Bayelsa State Nigeria. Department of Teacher Education, Faculty of Education, Niger Delta University, Wilberforce Island, Bayelsa State, Nigeria.

[32]Pagon, R. (2013). Student to Student Discourse on Selected Topics in Algebra: Its Effects to Students Achievement and Mathematical Anxiety. Unpublished Master's Thesis, Mindanao University of Science and Technology, Cagayan de Oro City.

[33] Parker, J. (2005). R.L. Moore: Mathematician and Teacher (Mathematical Association of America. P. vii.

[34] Piaget, J. (1973). To understand is to Invent. New York: Grossman

[35] Polizon, M. (2013). Mathematical Discourse and Journal Writing: Their Impact on Students' Mathematical Performance. Unpublished Dissertation, Mindanao University of Science and Technology, Cagayan de Oro City. 


\section{International Journal of Science and Research (IJSR) \\ ISSN (Online): 2319-7064}

Index Copernicus Value (2015): 78.96 | Impact Factor (2015): 6.391

[36] Rahman, Z. (2006). Conceptual Ability and Attitudes towards Algebra among Secondary School Students. Master of Education. Universiti Kebangsaan Malaysia.

[37] Roble, D. (2013). The Influence of Students' Personal Attributes on Students' Conceptual Understanding in Determining Area of Plane Regions in Integral Calculus. Unpublished Master's Thesis, Mindanao University of Science and Technology, Cagayan de Oro City.

[38] Samuelsson, J. (2008). The impact of teaching approaches on students' mathematical proficiency in Sweden. International Electronic Journal of Mathematics Education. Vol. 5, No. 2

[39] Sanchez, M. (2004). The Relative Effectiveness of Constructivism (Guided), Practical Work and Process Approaches in Teaching College Algebra. Unpublished Dissertation. Mindanao University of Science and Technology, Cagayan de Oro City.

[40] Seriña, MC. (2013). The Effects of Understanding by Design UbD and Dynamic Learning Program DLP on the Students' Conceptual Understanding in Mathematics II. Unpublished Master's Thesis, Mindanao University of Science and Technology, Cagayan de Oro City.

[41] Vygotsky, L.S. (1978). Mind in Society: The Development of the Higher Psychological Processes, Cambridge. MA: The Harvard University Press

[42] WoolFolk, A.E (1998). Educational Psychology. Seventh Edition. Allyn \& Bacon A Viacom Company. 160 Gould Street. Needham Heights, MA 02194, USA.

[43] Yaakob, M.J. (2007). Conceptual Knowledge in Mathematics and Its Relationship with Mathematics Achievement of Matriculation Students. Master of Education. Universiti Kebangsaan Malaysia.

[44]Zakaria, E., Solfitri, T., Daud, Y. \& Abidin, Z. (2013). Effects of Cooperative Learning on Secondary School Students' Mathematics Achievement. Creative Education 2013, Vol. 4, No. 2, pp. 98-100. Available: http:www.scirp.org/journal/ce)

[45]Zakaria, E. \& Iksan, Z. (2007). Promoting cooperative learning in science and mathematics education: A Malaysian perspective. Eurasia Journal of Mathematics, Science \& Technology, 3, 35-39.

\section{Author Profile}

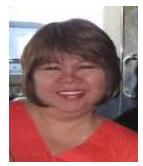

Vima Socorro J. Tandog finished her Master of Science in Teaching Mathematics in the University of Science and Technology of Southern Philippines (USTP) and completed the academic requirements leading to the degree of Doctor of Philosophy in Mathematical Sciences major in Mathematics Education in the same institution. Formerly, she was designated as the Dean of the College of Arts and Sciences (CAS) and currently she is now the Dean of the College of Science and Technology Education (CSTE) and she also teach in the graduate school of the same college.

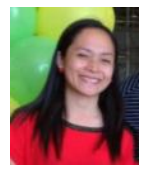

Maritess T. Jariolne graduated her Bachelor of Science in Agriculture in the Central Mindanao University and pursued her professional education in the Mindanao University of Science and Technology. Last March 2016, she finished her Master of Science in Teaching Mathematics in the University of Science and Technology of Southern Philippines (USTP). She has been in the public service as a secondary mathematics teacher in Cogon National High School, El Salvador City, Misamis Oriental since September 2012.

Volume 6 Issue 7, July 2017 www.ijsr.net 